RGSA - Revista de Gestão Social e Ambiental

Jan. - Abr. 2010, V.4, No.1, p. 80-91 ${ }^{1}$

www.gestaosocioambiental.net

\title{
GESTÃO AMBIENTAL E TECNOLOGIAS AMBIENTAIS: PRÁTICAS E BENEFÍCIOS EM UMA INDÚSTRIA ALIMENTÍCIA NO SUL DA BAHIA
}

\section{Luana das Graças Queiroz Farias}

Mestre em Planejamento Ambiental, Aluna do Programa de Pós-Graduação em Administração da Universidade Federal da Bahia,luanafffarias@hotmail.com

\section{Antônio Oscar Santos Góes}

Mestre em Administração, Docente da Universidade Estadual de Santa Cruz e Doutorando em Sociologia Econômica e das Organizações pelo Instituto Superior de Economia e Gestão-Universidade Técnica de Lisboa, oscargoes11@hotmail.com;

\section{Antônio Costa Silva Júnior}

Antônio Costa Silva Júnior, Contador, Mestre em Engenharia Ambiental pela Universidade Federal da Bahia e Doutorando em Engenharia Industrial pela Universidade Federal da Bahia, antoniocostasilvajunior@hotmail.com

\section{Resumo}

O presente trabalho objetivou apresentar as práticas e os benefícios, econômicos e ambientais decorrentes da adoção de tecnologias ambientais, em uma unidade industrial do segmento alimentício, no município de Itabuna, Bahia a partir de uma perspectiva de Gestão Ambiental. A metodologia da pesquisa utilizada constituiu de um estudo exploratório. A coleta de dados foi realizada mediante dados primários, através de entrevistas semi-estruturadas realizadas junto aos funcionários da empresa e secundários, com análise por meio de literatura, com ênfase nos temas gestão ambiental empresarial e tecnologias ambientais. Observou-se que a empresa investigada emprega tecnologia ambiental própria denominada “Água de Vaca” e tratamento de resíduos, mediante a casca de cacau "pellets”. A tecnologia aplicada revelou que há uma preocupação da organização no desenvolvimento de práticas voltadas para o acompanhamento dos processos produtivos. Quanto aos benefícios advindos dessa metodologia, concluí-se que eles aparecem tanto na perspectiva de redução de custos e resíduos, nas alternativas de boas práticas operacionais, visando à melhoria do desempenho ambiental, como na redução do consumo de água e/ou de energia e na capacitação dos colaboradores, consequentemente, reduzem-se os impactos para a saúde humana e o ambiente.

Palavras-Chave: Gestão Ambiental; Tecnologias Ambientais; Benefícios; Indústria Alimentícia; Região Sul da Bahia.

\footnotetext{
Abstract

This study aimed to present practices and the social, economic and environmental impacts of the adoption of environmental technologies, in an industrial unit of the food industry in the municipality of Itabuna, from a perspective of Environmental Management. The research

${ }^{1}$ Recebido em 01.11.2009. Aprovado em 19 .03.2010. Disponibilizado em 28.04.2010. Avaliado pelo sistema double blind review
} 
methodology used was an exploratory study. Data collection was performed using primary data through interviews with employees and the company side, with analysis by means of literature, with emphasis on corporate environmental management and technologies. It was observed that the investigated company employs its own methodology called "Cow Water" and waste through the cocoa husk pellets. The technology applied reveals that there is a concern of the organization in developing practices for monitoring production processes. As to the benefits from this methodology, it can be concluded that they appear from the perspective of reducing costs and waste, the alternatives of good operating practices in order to: improve environmental performance, reduce water and energy consumption and train our employees, and as a consequence, reduce the impacts to human health and the environment.

Keywords: Environmental Management, Environmental Technology, Benefits, Food Industry, Southern Bahia

\section{INTRODUÇÃO}

$\mathrm{O}$ ambientalismo, a partir do final do século $\mathrm{XX}$, adquire novas feições com a vinculação das empresas ao conceito de Desenvolvimento Sustentável e à idéia de um mercado verde. A preocupação com o meio ambiente passou, então, a ser considerada uma prioridade em qualquer tipo de organização.

Nota-se que as céleres mudanças que atingem a sociedade humana vêm exigindo dos gestores e empreendedores capacidade múltiplas para administrarem de acordo com os novos cenários e contingências. Com o fenômeno da globalização, registrou-se um avanço sem precedentes na evolução da competitividade e, conseqüentemente, na necessidade do aumento da produtividade, eficiência e eficácia nos resultados empresariais.

Os novos tempos, caracterizados pela busca de posições competitivas favoráveis e intensas preocupações com o meio ambiente, tem influenciado as organizações de diferentes segmentos a agirem de forma pró-ativa com relação às questões ambientais em detrimento das posturas reativas.

A forma como a empresa atua em relação aos problemas ambientais em decorrência das suas atividades pode resultar em três diferentes abordagens, controle da poluição, caráter tipicamente reativo; prevenção da poluição, postura reativa e pró-ativa; estratégica, atitude também reativa e pró-ativa, em que os problemas ambientais são tratados como uma das questões estratégicas da empresa e, por conseguinte, relacionadas com a busca de uma situação vantajosa no seu negócio atual ou futuro (BARBIERI, 2006).

Diferentes abordagens, tecnologias e práticas de Gestão Ambiental procuram sensibilizar gestores dentro das organizações para implementarem estratégias ambientais aplicadas aos processos, produtos e serviços para minimizar os impactos sobre o meio ambiente, demonstrando a possibilidade de se obter lucro com o meio ambiente.

O objetivo maior da Gestão Ambiental é buscar permanentemente a melhoria da qualidade ambiental dos serviços, produtos e ambiente de trabalho de qualquer organização pública ou privada. Debater as questões ambientais é pensar no futuro das próximas gerações e do planeta, no modo de vida das pessoas em termos de qualidade do ar, da água, do melhor aproveitamento dos recursos naturais, na proteção à vida e do uso parcimonioso dos recursos naturais enquanto fonte de energia.

A Gestão Ambiental, nos últimos anos, tem adquirido cada vez mais uma posição destacada, em termos de competitividade, devido aos benefícios que proporciona, tanto aos processos produtivos como a melhoria da reputação empresarial, enquanto benefício intangível. 
Dias (2007), argumenta que o grau de competitividade de uma empresa está associado a um conjunto de fatores, variados e complexos, que se inter-relacionam e são reciprocamente dependentes, tais como: custos, qualidade dos produtos e serviços, nível de controle de qualidade, capital humano, tecnologia e capacidade de inovação.

No tocante à competitividade empresarial, duas variáveis ambientais são proeminentes: a gestão ambiental de processos e de produtos. A Gestão Ambiental de processos se caracteriza como uma das principais ferramentas para obtenção de melhores resultados, através da descoberta de novos componentes e novas matérias-primas mais confiáveis, com destaque para as tecnologias ambientais, que trazem resultados competitivos em termos de redução dos custos, além de certificação de processos. Em relação à Gestão Ambiental de produto, as principais ferramentas são a análise do ciclo de vida, a certificação dos produtos (selos ecológicos) e o ecodesign.

Esse novo panorama tem exigido de segmentos como o comércio e a indústria, até mesmo organismos internacionais, que reconheçam o manejo do meio ambiente como uma ação prioritária, no sentido de buscarem alternativas tecnológicas ambientalmente seguras e matérias-primas menos tóxicas como fator determinante e fundamental do Desenvolvimento Sustentável.

A organização empresarial ocupa um lócus privilegiado no sistema capitalista, em que são observadas as mudanças nele ocorridas, desde o seu surgimento até os tempos atuais. A empresa, em face de sua importância nas novas relações estabelecidas pelo mercado, na formulação das políticas de preservação ambiental e de promoção social, com destaque para as organizações do setor industrial, demanda com mais intensidade recursos naturais e energéticos, além de ocupar um papel essencial na oferta de trabalho (PINHEIRO, 2006).

As tecnologias ambientais têm como objetivo a conservação de materiais, água e energia, eliminação de materiais tóxicos e perigosos, redução da quantidade e toxicidade de todas as emissões e resíduos, na fonte, durante a fábrica e redução do impacto ambiental para a saúde humana, durante todo o ciclo, ou seja, desde a extração da matéria-prima, na manufatura, no consumo luso e na disposição final.

Adoção de tecnologias ambientais como a Tecnologia Mais Limpa (TML), de acordo com Dias (2007), visam: amparar as redes de organizações que desenvolvem estratégias de TML; expandir as possibilidades de melhoria ambiental das empresas mediantes a educação e a capacitação; sustentar projetos que sirvam de modelo de referência, controle democrático e responsabilidade continuada do produtor.

A UNIDO-UNEP com intuito de disseminar as diretrizes do programa de tecnologia ambiental e demonstrar que é possível proteger o meio ambiente e obter ganhos econômicos, fomenta a criação dos Centros Nacionais de Produção Limpa (CNTL) em países em desenvolvimento, os quais têm o papel de capacitar pessoas e implementar esta metodologia nas organizações, em diversos setores de atuação, a exemplo das indústrias, agricultura e serviços.No Brasil, em 1995, o Serviço Nacional de Aprendizagem Industrial (SENAI), do Rio Grande do Sul, foi selecionado para a implantação do CNTL no Brasil, localizado em Porto Alegre. A partir de então, o CNTLISENAI-RS começou a divulgar e implantar as tecnologias ambientais no contexto empresarial, em consonância com a metodologia Ecoprofit, definida pela UNIDO- UNEP.

Assim, o artigo tem por objetivo apresentar as práticas de tecnologias ambientais empregadas por uma unidade industrial do segmento alimentício, no município de Itabuna e os benefícios nos processos produtivos, que permitem colaborar para a solução dos problemas ambientais, já que a prioridade do procedimento está baseada na identificação de opções de não geração dos resíduos, a partir do modelo de Gestão Ambiental adotado. É, por conseguinte, divulgar uma prática preventiva da poluição, que, além disso, leva à economia de 
água, de energia e de matérias-primas, com aumento significativo de lucratividade e competitividade.

O presente artigo está estruturado em quatro seções, iniciando com esta introdução. Na seqüência, apresenta-se as considerações teóricas do estudo, com ênfase na definição e no papel da gestão ambiental empresarial e nas tecnologias ambientais adotadas com o intuito de melhorar a performance ambiental das empresas. Em seguida, destaca-se o caso analisado, a metodologia aplicada para o desenvolvimento da pesquisa. A partir dos dados coletados na empresa investigada, faz-se a descrição e análise dos dados. Por último, apresentam-se as considerações finais.

\section{CONSIDERAÇÕES TEÓRICAS}

\subsection{GESTÃO AMBIENTAL EMPRESARIAL}

O maior desafio, quando se trata de discutir a Gestão Ambiental Empresarial (GAE) é de prevenir e controlar os impactos de um empreendimento sobre o meio ambiente e compatibilizar o crescimento econômico com a preservação ambiental, já que, quanto menos resíduos as indústrias geram, menor é o gasto na produção. $\mathrm{O}$ assunto primordial que estimula todo tipo de empresa pública ou privada é como permanecer viável e continuar operando de forma amigável como o meio ambiente (KINLAW, 1997).

A questão ambiental está sendo encarada com bastante relevância pelas organizações, devido às pressões da globalização que levou alguns blocos econômicos e países mais ricos a enfatizarem a preservação do meio ambiente e a diminuição da poluição no planeta, de modo a encarar com novas perspectivas as empresas que desenvolvem o conceito de desenvolvimento ambientalmente sustentável. As ações ambientais das empresas resultam de uma ação reativa na qual ela centra suas atenções nos efeitos negativos que seus produtos e processos produtivos possam causar ao meio ambiente (BARBIERE, 2006).

A Gestão Ambiental é bastante abrangente, sendo usada freqüentemente para designar ações ambientais em determinados espaços geográficos: bacias hidrográficas, parques, e reservas florestais, áreas de proteção ambiental e muitas outras modalidades de gestão que incluam os aspectos ambientais. Já o termo GAE é direcionado a um conjunto de políticas, programas e práticas administrativas e operacionais da organização, visando à saúde e a segurança das pessoas e a proteção do meio ambiente através da eliminação ou minimização de impactos negativos decorrentes da implantação ou da operação da organização em determinada área.

Ampliando as discussões sobre o conceito e importância da GAE, Takesky Tachizawa, no livro Gestão Ambiental e Responsabilidade Social Corporativa (2002) propõe um modelo de gestão ambiental e de responsabilidade social que leva em consideração as variáveis ambientais e as definições dos interessados na empresa (stakeholders), iniciam-se com as decisões estratégicas, com ênfase para o delineamento dos objetivos da corporação e das estratégias globais (genéricas) da organização.

Por outro lado, Kinlaw (1997) aponta pontos principais quanto à competitividade e o meio ambiente. Um ponto diz respeito às organizações enxergarem a questão ambiental como uma oportunidade competitiva. Maior será a probabilidade de uma empresa sobreviver e dar lucro, quanto maior for a sua atenção aos cuidados com o meio ambiente. Outro ponto é dado pela ênfase da questão ambiental como uma oportunidade de lucro, controlando os danos causados a natureza e suas repercussões perante os consumidores.

A empresa possui uma forte relação com o meio ambiente, seja extraindo matériaprima, seja consumindo energia ou depositando os seus resíduos. A empresa transcende as fronteiras e os limites do nacionalismo, influenciando as decisões políticas e sociais A conscientização ambiental levou as organizações a uma maior demanda pela qualidade total. A velocidade com que as empresas tomam consciência da necessidade de preservar o meio 
ambiente é muito lenta para os ambientalistas, porém para alguns líderes empresariais, está indo rápido demais (ANDRES, 2001).

Para Kinlaw (1997), cada vez mais as empresas direcionam os seus negócios de forma mais sensível com relação ao meio ambiente. Várias são as formas de fortalecer as organizações frente à questão ambiental tornando-as mais competitivas. Dentro dessa ótica, as organizações podem agir de forma pró-ativa, reduzindo a quantidade de material usado nos produtos e serviços, reduzindo o consumo e o custo de energia, criando novos produtos e serviços para novas oportunidades de mercado, reduzindo os riscos de grandes desastres ambientais, aplicando e adquirindo tecnologias novas, bem como, de uma forma geral, melhorando a imagem pública da empresa.

Na literatura, autores como Barbieri (2006), Souza (2000) e Donaire (1999) complementam este argumento, quando o assunto são as pressões que têm atuado sobre as empresas no sentido de influenciá-las na promoção de mudanças positivas nas suas condutas ambientais, com resultados evidentes sobre as estratégias empresariais. Para estes pesquisadores as pressões têm origem, sobretudo dos seguintes grupos: regulamentação jurídica, sociedade civil organizada, mercado de produtos e nas fontes de recursos naturais.

Nos últimos anos, essa preocupação passou a caracterizar as organizações que buscam o reconhecimento do mercado como sendo ambientalmente correta, tendo responsabilidade ambiental, planejando corretamente a produção e a disposição de seus resíduos gerados.

\subsection{TECNOLOGIAS AMBIENTAIS}

Em conseqüência das inúmeras pressões ambientais que recaem sobre as empresas, elas estão desenvolvendo tecnologias ambientais que visam melhorar o seu desempenho ambiental, no que concerne ao aprimoramento dos processos, maior atenção com os recursos e resíduos e procurando novos produtos e tecnologias. A esse conjugado de estratégias com o intuito de melhorar a performance ambiental das empresas, de forma a sintonizá-la com as demandas externas e internas, têm sido atribuída inúmeras denominações, como Tecnologia Limpa, Tecnologia Mais Limpa, Tecnologia de baixo desperdício, Produção Limpa e Produção Mais Limpa (SOUZA, 2000).

Para Lenzi (2006) as tecnologias ambientais podem ser classificadas em: Controle de Poluição ou end-of-pipe e Tecnologias Mais Limpas. A primeira tem suas normas tecnológicas voltadas para o princípio da correção, a captura de emissão de poluentes e a ausência de modificação do sistema produtivo. Por conseguinte, a segunda objetiva evitar ou restringir as emissões antecipadamente, tendo em vista a ação sobre as causas da degradação ambiental e não sobre os seus efeitos, baseando-se no princípio de prevenção.

Nesse sentido, a UNIDO/UNEP(2001) e Lenzi (2006) agruparam as tecnologias ambientais em três grupos: a) Tecnologias Limpas (Clean Technologies)- refere- se à utilização de tecnologia que não polui o meio ambiente. Geralmente é utilizada como sinônimo de Tecnologias Mais Limpas ou de Produção Mais Limpa; b) Tecnologias Mais Limpas (Cleaner Tecnologies)- tem a finalidade de proteger e ou conservar o meio ambiente, impedindo o desperdício de recursos e a degradação ambiental, com vistas a atender o Desenvolvimento Sustentável; c) Tecnologias Fim de Tubo (End-of-Pipe Technologies)abordam tecnologias empregadas para o tratamento, a minimização e a inertização de resíduos, efluentes e emissões. São exemplos de Tecnologias Fim de Tubo, os filtros de emissões atmosféricas, as estações de Tratamento de Efluentes Líquido (ETE) e as tecnologias de tratamento de resíduos sólidos.

Na tentativa de ampliar esses conceitos, o Conselho Mundial Empresarial para o Desenvolvimento Sustentável (WBCSD, 2006), definiu Tecnologia Mais Limpa como uma aplicação contínua de uma estratégia técnica, econômica e ambiental integrada aos processos, produtos e serviços, objetivando o aumento da eficiência no uso das matérias-primas através 
da não-geração, minimização ou reciclagem de resíduos e emissões com benefícios percebidos na saúde ocupacional, no meio ambiente e na economia. Ainda incluem nessa abordagem a análise dos 3R's: redução, reutilização e reciclagem.

A abrangência dada a esses conceitos e a sua apropriação inadequada resulta, em parte, definições e uso incorreto destas metodologias. Os autores deste artigo propõem o uso do termo Tecnologia Mais Limpa, pois agem na prevenção e geração de resíduos, efluentes e emissões, sensibilizando e engajando toda a instituição na tentativa de atingir o Desenvolvimento Sustentável.

\subsubsection{Tecnologia Mais Limpa}

Para Lenzi (2006) e Batista (1993) emprego de Tecnologia Mais Limpa é mais lógico que as demais, uma vez que prioriza a prevenção e minimização dos resíduos gerados, sugerindo que as empresas atuem na fonte geradora e busquem alternativas para um novo modelo de tecnologia ambiental, em favor do Desenvolvimento Sustentável. Dias (2007) complementa, argumentando que esse conceito está entre os mais discutidos pelas organizações empresariais internacionais e nacionais, pois visa atingir, também, benefícios sustentáveis, ou seja, econômicos, sociais e ambientais.

A Tecnologia Mais Limpa tem caráter preventivo e sistêmico, excluindo as ações que envolvem apenas o tratamento de resíduos ou reciclagem, a exemplo das tecnologias de endof-the-pipe ou fim-de-tubo. Nesse contexto, estratégias ambientais convencionais que visam atender às exigências ambientais nos aspectos legais deixam de ser observadas como única alternativa para melhorar o desempenho ambiental, e também porque representam opções onerosas para as empresas do ponto de vista econômico.

No entanto, para Lenzi (2006) a adoção de Tecnologias Mais Limpa possibilita à empresa mais informações e conhecimentos sobre o seu processo de manufatura através do monitoramento constante e do desenvolvimento de práticas baseadas na ecoeficiência de produção, gerando indicadores ambientais e de processos. Ou seja, a Tecnologia Mais Limpa é vista como uma estratégia preventiva integrada aos processos, aos produtos e aos serviços com vistas a reduzir os riscos para a saúde humana e para o meio ambiente.

A implementação da Tecnologia Mais Limpa é analisada como uma visão sistêmica, em que à empresa identifica necessidades de pesquisa aplicada, informação tecnológica e programas de capacitação. Ademais, integra-se aos Sistemas de Qualidade, Gestão Ambiental, Segurança e Saúde Ocupacional.

Na literatura sobre o assunto, US $\ E P A$ (1998) apud Filho (2007) aponta os benefícios advindos da adoção de Tecnologias Mais Limpas, agrupando-os em quatro categorias: a)Redução de custos operacionais - análise sistemática dos processos produtivos visando a uma ação preventiva à geração de resíduos e desperdícios de qualquer natureza;b) Ampliação e melhoria da imagem da empresa- preocupação da empresa em agir com pro-atividade, passando a empresa a ser benquista pelo mercado, com rótulos de empresa compromissada com o meio ambiente e o bem-estar da sociedade; c)Diminuição da responsabilidade civil e criminal - proporciona uma diminuição dos aspectos que escapariam dos parâmetros legais. Envolve, também, a transparência e abertura de informações pelas empresas e organizações do setor público, num estímulo à prática de benchmarking e à publicação dos relatórios, com o objetivo de contribuir para a elevação dos padrões ambientais; d)Preparação das empresas para a implantação de SGA baseada na ISO 14000 - a PML, auxilia as empresas a reduzirem a geração de resíduos, bem como a possibilidade de utilizar esta metodologia como ferramenta para garantir a melhoria continua, como estabelecido na norma ISO 14001. 


\section{O ESTUDO EM UMA UNIDADE INDUSTRIAL DO SEGMENTO ALIMENTÍCIO LOCALIZADA NO SUL DO ESTADO DA BAHIA}

\subsection{A PESQUISA}

O presente estudo utilizou o tipo de pesquisa exploratória, com o objetivo de proporcionar uma visão geral, de tipo aproximativo, acerca dos temas Gestão Ambiental e Tecnologias Ambientais. No entendimento de Gil (2002, p. 44), a pesquisa exploratória "constitui-se num estudo preliminar que visa obter maior familiaridade com o fenomêmo que se pretende investigar e, limitando-se a definir objetivos e buscar informações sobre determinado assunto".

A pesquisa foi realizada no período de 10 a 20 de novembro de 2008 em uma unidade industrial localizada no município de Itabuna, Bahia, responsável pelo abastecimento de leite em pó do país e com representatividade acentuada nas regiões Norte e Nordeste. Essa empresa atende clientes exigentes, tanto no mercado nacional como internacional o que estimula a criação de programas de melhoria da qualidade ambiental de seus produtos e processos.

No que tange à coleta de dados primários, ela foi obtida através de entrevistas semiestruturadas realizadas com gestores da empresa. Já os secundários, foram alcançados por meio de material já publicado em livros, artigos, periódicos e em bancos de teses, possibilitando a elaboração da fundamentação teórica do trabalho.

Segundo informações levantadas junto aos gestores, o quadro funcional da empresa era composto por noventa e oito (98) colaboradores, incluindo gerentes, supervisores, analista de processo, programadores, mecânicos, operadores de máquinas, analistas de laboratório, estagiários, técnicos administrativos e apoio logístico. No entanto, o total de gestores da empresa correspondeu a quinze (15), os quais representaram a população da pesquisa.

Para amostra, utilizou-se a modalidade não probabilística intencional, pois de acordo com Marconi e Lakatos (2001), a mesma não assume tratamento estatístico e o pesquisador busca levantar a opinião de determinados elementos da população. Quanto à delimitação da amostra, foram selecionados dez (10) gestores da empresa atuantes em áreas relacionadas ao meio ambiente, a saber: compras, qualidade, segurança do trabalho, latoaria, manutenção, meio ambiente, eletromecânica, embalagens e sistemas de gestão.

E por fim, os dados foram tratados por meio de abordagem qualitativa com o objetivo de apresentar e interpretar os resultados obtidos, conferindo validade e consistência, como pôde ser visto na seção posterior.

\subsubsection{Os resultados}

A pesquisa evidenciou que a empresa em estudo adota o conceito de Desenvolvimento Sustentável como referência para suas práticas gerenciais. A empresa implementou um sistema integrado de gestão, representados pela adoção das quatro normas: ISO 9.000, 14.000, 22.000 e OHSAS 18.001.

A instituição adota uma política de Meio Ambiente Corporativo, concebidos através de Sistema de Gestão Ambiental próprio utilizado até novembro de 2007. Isso fortalecia, principalmente, o seu relacionamento com seus stakeholders, em especial, os que estejam dispostos a aplicar os padrões de qualidade em seus produtos, além de trabalhar com gestão integrada, formação de pessoal e transferência de tecnologias.

Na perspectiva de Gestão Ambiental a empresa é orientada pelos Sistemas de Gestão Ambiental, apresentados em duas dimensões: a) Sistema de Gerenciamento Ambiental Interno (NEMS)- a empresa tem como função primária a transformação de matérias-primas perecíveis em produto acabado, com isso surgiu a necessidade de implantação de um sistema que satisfizesse as expectativas dos consumidores, a segurança dos colaboradores e qualidade e valor;b) Sistema de Gestão Integrado (SGI) - Ao longo dos anos percebeu-se a necessidade da empresa se adequar ao mercado, devido à pressão de alguns clientes que exigiam a 
certificação ISO e pelo comprometimento com seus clientes e consumidores, através da excelência nos serviços prestados, para isso foi preciso investir num sistema integrado de certificação e dentro das normas da ISO. São eles a ISO 9000, ISO 14000, OHSAS 18000 e a ISO 22000.

Para os gestores, o NEMS é um Sistema de Gestão Ambiental interno aplicado a todas as unidades desta organização. Sua metodologia e aplicabilidade são pertinentes aos descritos pela ISO. Alguns aspectos significativos do NEMS são o código de ética estabelecido, análises de danos ambientais e a aplicação da legislação vigente. Ainda hoje, o NEMS é utilizado na empresa, mesmo após a implantação de um sistema integrado. Para os entrevistados, o SGI demonstrou o comprometimento da empresa com o meio ambiente, a qualidade, a saúde e a segurança, bem como a preocupação com a eliminação de desperdícios, significando a diminuição na geração de resíduos e nos custos de produção.

A realidade descrita acima está contida no entendimento de Gestão Ambiental integrada, destacada pela maioria dos autores da área ambiental. Por exemplo, Souza (2000) atribui as diretrizes ambientais e a forte internacionalização dos mercados como os grandes impulsionadores da adoção destes modelos. Complementando Barbieri (2006), afirma que a implantação de um Sistema de Gestão é pertinente as empresas comprometidas com o meio ambiente e que este sistema esteja integrado ao plano estratégico da organização.

A implantação do SGI nessa indústria conforme pesquisas desenvolvidas por Farias et al. (2007) e Farias, Sobrinho e Barreto (2008) mostraram que os procedimentos de Gestão Ambiental visam : Desenvolver alternativas de boas práticas operacionais visando a melhoria do desempenho ambiental como redução do consumo de água e/ou de energia; Realizar ações voltadas para a educação ambiental de funcionários como palestras, seminários e folder’s e envolver programas de educação ambiental, além de planos de ação, em casos de emergência.

Segundo relato dos entrevistados os meios de divulgação da Gestão Ambiental na empresa favorece "o conhecimento acerca dos sistemas de gestão e das tecnologias ambientais aplicadas”. No entanto, os gestores acreditam que os meios mais eficientes acontecem através de treinamento, informativo interno, ações internas além de outros meios como internet, intranet e jornais que ficam como fonte de divulgação menos frequentes.

Para os gestores os programas de Gestão Ambiental que representam o uso dos recursos naturais no âmbito interno e externo são constituídos pelos: resíduos, efluentes, consumo de água e energia, Benchamarketing e controle ambiental, conforme Quadro1 abaixo:

Quadro 4: Programas e ações de Gestão Ambiental adotadas pela empresa

\begin{tabular}{|l|l|}
\hline PROGRAMAS & AÇÕES \\
\hline Resíduos & $\begin{array}{l}\text { Reciclagem e destinação final adequada conforme a legislação } \\
\text { vigente }\end{array}$ \\
\hline Efluentes & Tratamento biológico através da PTAR, tratamento de efluentes \\
\hline Consumo de água e energia & Programas de redução de consumo de energia e água \\
\hline $\begin{array}{l}\text { Benchmarking aos produtos e } \\
\text { usuários dos produtos }\end{array}$ & A empresa a adota as melhores práticas internas e externas \\
\hline Controle ambiental & $\begin{array}{l}\text { A empresa possui uma ferramenta chamada Aspimp- aspectos e } \\
\text { impactos ambientais }\end{array}$ \\
\hline
\end{tabular}

Dados: Elaboração própria.

Já no que concerne a adoção de tecnologia ambiental, a empresa adotou um método próprio denominado “Água de Vaca”. De acordo com as características dessa metodologia, a mesma se aproxima do padrão de Tecnologia Mais Limpa apresentado neste estudo, uma vez que seus efeitos alcançam toda a extensão da cadeia produtiva e está integrada aos Sistemas de Qualidade, Gestão Ambiental, Segurança e Saúde Ocupacional. 
Acrescenta-se que o uso dessa tecnologia associada aos processos e produtos é caracterizado pela adoção de estratégias para reduzir e eliminar já na fonte a produção de qualquer tipo de poluição, e ao mesmo tempo, racionaliza o uso de recursos naturais (princípio da ecoeficiência). Sua ênfase é voltada para as causas da degradação ambiental e não sobre seus efeitos, enaltecendo assim, seu princípio fundador: a prevenção.

A terminologia “Água de Vaca” foi utilizada internamente pelo fato de ser um recurso extraído do próprio leite da vaca através de um aparelho especial chamado "condensador a vácuo” (processo de condensação no qual se extrai 70\% da água do leite). A condensação representa uma fase da produção de leite em pó, em que se retira parte da água do leite por evaporação sob pressão reduzida (vácuo).

A unidade de Itabuna, em função da tecnologia “Água de Vaca” deixou de extrair 84 mil metros cúbicos anuais de água do Rio Cachoeira, pois atualmente a água retirada do leite (após tratamento) é reaproveitada nos processos produtivos da fábrica, assegurando uma redução no consumo de energia com a diminuição do uso das bombas de captação junto ao Rio, gerando benefícios econômicos e ambientais diretos para a empresa e para o meio ambiente. Segundo relato dos entrevistados o "bom emprego dessa tecnologia ajudou a reduziu 16 mil metros cúbicos anuais no uso de água utilizada na alimentação das caldeiras, volume suficiente para uma população de cerca de 107 mil pessoas em um dia”.

Outro benefício resultante dessa tecnologia foi a facilidade do tratamento da água removida do leite, demandando menos produtos químicos para sua reutilização, o que proporciona ganhos econômicos e ambientais significativos, segundo os gerentes consultados.

De acordo com a pesquisa essa tecnologia ambiental objetiva: reaproveitar um recurso natural disponível resultante do processo produtivo; economizar energia para transporte e captação de água do Rio Cachoeira; destinar de forma adequada resíduos sólidos; reduzir o consumo de combustíveis fósseis na caldeira de biomassa; aperfeiçoar os potenciais destes resíduos disponíveis; minimizar os possíveis impactos ambientais e auxiliar na promoção do Desenvolvimento Sustentável na região.

A tecnologia “Água de Vaca” pôde ser descrita em quatro etapas interdependentes. Inicialmente quando a matéria-prima (leite in natura) chega à unidade fabril ela é submetida a várias análises para validar a qualidade do produto conforme exigências técnicas e legais (temperatura, acidez, alizarol, crioscopia, substâncias estranhas, fraudes, antibióticos, soro e outros) e posteriormente, é encaminhada para as seguintes etapas:

- Segunda etapa - Acondicionamento do leite in natura em recipientes chamados de silos para formação dos lotes ou partidas de 30.000 a 40.000 litros de padronização/receita ou produtos como: leite in natura, vitaminas, leite condensado, lecetina de soja );

- Terceira etapa - Processamento de evaporação e envio das partidas ou lotes formados. Nesse momento, as partidas ou lotes são transportados através de bombas para o evaporador de múltiplo efeito. A partir de então, o leite padronizado recebe calor de forma indireta (aquecimento a vapor vindo das caldeiras) a linha sob vácuo a 760 Mmhg(milímetro de mercúrio a nível do mar) ou seja, pressão negativa, o produto evapora a 70c sem perder as propriedades organolépticas e proteínas(mantém-se todas as propriedades do leite).Por fim, 70\% da água do leite é transformado em vapor dentro do equipamento;

- Quarta etapa - Fornecimento deste vapor (água do leite). Aqui foi observada a transformação da água do leite em água (denominada internamente de “Água de Vaca”), no qual foi extraído através de bombas e conduzido para a Estação de Tratamento de Água (ETA). No entanto, no passado essa água seria descartada direto para a Estação de Tratamento de Efluentes (ETE). 
Outra ação importante da empresa vinculada ao tratamento de resíduos foi da casca de cacau "pellets". A organização compra cacau em amêndoa da região Sul da Bahia e de outros países, a exemplo da Costa do Marfim e de Gana. O processo de produção dos semifabricados de cacau começa com o recebimento das favas de cacau que chegam em sacas de sessenta (60 kg). Posteriormente, através de amostragem, as favas são selecionadas e analisadas para eliminação das possíveis impurezas e são separadas das cascas e reduzidas a pedaços, cada vez menores.

Em seguida, as cascas são prensadas e transportadas em "pellets” e são queimadas numa caldeira especial, gerando energia, vapor que é utilizado como energial biomassa.Consegue-se, com essa prática, economizar cerca de $30 \%$ do consumo de combustíveis fosseis, com a utilização da casca do cacau na geração de energia. Os resíduos gerados a partir da queima dos "pellets" de cacau que denomina de cinzas são ricos de minerais como fósforo, potássio, onde são catalisados na formação de compostagem e agricultura.

\section{CONSIDERAÇÕES FINAIS}

A análise do tema em uma unidade industrial no sul do Estado da Bahia, em termos gerais, sinaliza que a introdução de práticas e modelos de gestão ambiental empresarial no segmento industrial é um processo contínuo e sistemático.

A necessidade de adequar os seus produtos aos padrões externos estimulou a indústria a atender a necessidades de seus clientes e a cumprir a legislação ambiental. A pressão mercadológica foi o fator determinante para a organização pesquisada adotar modelos de SGA que atendessem o mercado tanto nacional, quanto internacional e superasse as expectativas de clientes, fornecedores, stakeholders em geral. Na década de 80, a organização adotou o modelo NEMS, criado internamente e que atende todos os requisitos legais e ambientais pertinentes a gestão ambiental. O NEMS passou a vigorar em todas as unidades como um diferencial em relação ao comprometimento da empresa com o meio ambiente.

Após a implantação do Sistema de Gestão Integrado, observou-se um compromisso mais efetivo com o meio ambiente, a saúde ocupacional, a qualidade na produção e as normas de segurança para a organização. Priorizados na reputação institucional, na satisfação dos clientes com a qualidade dos produtos e nas práticas ambientalmente corretas.

A análise dos dados obtidos junto à organização demonstrou que a introdução de tecnologias ambientais, a exemplo da "Água de Vaca” pôde ser considerada um tipo de Tecnologia Mais Limpa, atendendo aos quesitos de: redução de custos operacionais; análise sistemática dos processos produtivos, visando ações preventivas; ampliação e melhoria da imagem da empresa; identificação das necessidades da empresa em informação e programas de capacitação.

Observou-se através dessa tecnologia ambiental "Água de Vaca” e do tratamento de resíduos, mediante a casca de cacau "pellets" que há uma preocupação da organização no desenvolvimento de práticas voltadas para o acompanhamento dos processos produtivos. Em particular, a metodologia "Água de Vaca” foi utilizada na alimentação das caldeiras e nos processos de potabilização ( água reciclada) na Estação de Tratamento, obtendo assim, um importante ganho ambiental.

Quanto aos benefícios advindos desta metodologia, concluí-se que eles aparecem tanto na perspectiva de redução de custos e resíduos, as alternativas de boas práticas operacionais visando à melhoria do desempenho ambiental como na redução do consumo de água e/ou de energia e na capacitação dos colaboradores através de programas de educação ambiental e conseqüentemente, reduzem-se os impactos para a saúde humana e o ambiente.

O escopo desta pesquisa foi circunscrito, porém serve como referência para futuras pesquisas na área de Gestão Ambiental Empresarial, como, por exemplo, o desenvolvimento 
de novas metodologias de tecnologias ambientais, aprofundamento dos aspectos metodológicos, levando em consideração as particularidades do segmento ou organização e o desenvolvimento de pesquisas mais amplas da temática no contexto da proposta elaborada pela Tecnologia Mais Limpa. Por fim ressalta-se que suas inferências, achados e conclusões aqui evidenciadas não podem ser generalizadas, mas devem ser entendidas como tendências indicativas da evolução da área pesquisada.

\section{REFERÊNCIAS}

Andrade, T. LC. S.; Chiuvite, T. B. S. (2004). Meio Ambiente: um bom negócio para a indústria. São Paulo, SP, Editora Tocalino.

Andres, L. F.( 2001). A gestão ambiental em indústrias do vale do taquari: Vantagens com o Uso das Técnicas de Produção Mais Limpa. Dissertação (Mestrado em Administração). Universidade Federal do Rio Grande do Sul, Porto Alegre, Brasil.

Barbieri, J. C. (2006). Gestão Ambiental Empresarial: conceito, modelos e instrumentos. São Paulo, Editora Saraiva.

Batista, P.N. (1993). O desafio brasileiro: a retomada do desenvolvimento em bases ecologicamente sustentáveis. Política Externa, v.2,n.3,p.29-42, dez.

Dias, R. (2007). Gestão ambiental: responsabilidade social e sustentabilidade. ( $1^{\text {a }}$.Ed.). São Paulo: Atlas.

Donaire, D. (1999). Gestão Ambiental na Empresa. (2 ${ }^{\text {a }}$ Ed). São Paulo: Atlas.

Farias, L. G.Q et.al., Avaliação Ambiental das Empresas do Setor Alimentício: o caso do SGA adotado pela DPA. . Recuperado em 10 março,2008, de< htttp: $\mid<$ www.seminariouesc.br $>$.

Farias L. G.Q; Sobrinho, S.A; Barreto, S.C. Meio Ambiente e Gestão Ambiental nas Indústrias do Sul da Bahia: estudos preliminares sobre a adoção do SGA. Recuperado em 30 abril, 2008, de < htttp: $<$ www.conferenciadaterra.com.br.

Filho, I. B., L(2007). Gestão Ambiental dos produtores rurais e indústrias alimentícias do eixo, Itabuna - Ilhéus. Dissertação (Mestrado em Desenvolvimento Regional e Meio Ambiente), Universidade Estadual de Santa Cruz, Ilhéus, Brasil.

Gil. A.C. (2002). Como elaborar projetos de pesquisa.( $4^{\text {a }}$ Ed.). São Paulo: Atlas. História das Normas de Gestão Ambiental. Recuperado em 19 maio, 2008, de <http://www.producao.ufrgs.br/arquivos/disciplinas/409_texto_estudo_14001.pdf>.

Kinlaw, D. (1997). Empresa Competitiva e ecológica: desempenho sustentado na era ambiental. São Paulo: Makron Books.

Kraemer, M. E. P. Responsabilidade social corporativa: uma contribuição das empresas para o desenvolvimento sustentável. Recuperado em 18 setembro, 2007, de http://www.gestaoambiental.com.br/articles.php?id=66.

Lakatos, E. M.; MarconI, M. A. (2001). Fundamentos da metodologia científica. ( $4^{\text {a }}$ Ed.). São Paulo, Editora Atlas. 
Lenzi, C. L.(2006). Sociologia ambiental: risco e sustentabilidade na modernidade. São Paulo: Edusc.

Lemos H. M. (1996). Normas da Série NBR ISO 14000, Desenvolvimento Sustentável. Brasília, IBAMA.

MANUAL. Sistema Nestlé de Gestão Ambiental - NEMS FÁBRICAS, Manual interno. Mello, C.A; Nascimento, L.F. Produção Mais Limpa: um impulso para a inovação e a obtenção de vantagens competitivas - o de caso na cabine de pintura de uma empresa do setor metal-mecânico. Recuperado em 30, março, de <http://www.abepro.org.brlbibliotecalENEGEP2002_TR100_0846.pdf._

Pinheiro, J. M. Gestão Socioambiental: conceitos, modelos e práticas. Salvador (BA).( 2006). . Recuperado em 10 março, 2008, de< http://www.aulaadm.pro.br>

Santos, J.C. (2008). A Análise do significado da gestão ambiental desenvolvida pela indústria DPAM/NESTLÉ, segundo a visão dos gestores, colaboradores e da comunidade no município de Itabuna, Bahia. Estudo preliminar (Monografia), União Metropolitana de Educação e Cultura.Itabuna, Brasil.

Schultze, J.P.S. (2001).Mineração e a Questão Ambiental: estudo de caso da mina de carvão de Candiota (RS).Dissertação (Mestrado em Administração), Universidade Federal do Rio Grande do Sul. Porto Alegre, Brasil.

Seiffert, M. E. B.(2007). ISO 14001 Sistemas de Gestão Ambiental: implantação objetiva e econômica. ( $3^{\mathrm{a}}$ Ed.). São Paulo, Editora Atlas.

SERVIÇO NACIONAL DE APRENDIZAGEM INDUSTRIAL- RIO GRANDE DO SUL. (2003). Implementação de Programas de Produção Mais Limpa. Porto Alegre, Centro Nacional de Tecnologias Limpas. (Séries Manuais de Produção mais Limpa).

. (2003). Sistema de Gestão Ambiental e Produção mais limpa. Centro

Nacional de Tecnologias Limpas, (Séries Manuais de Produção mais Limpa).

Souza, R.S. (2000). Entendo a questão ambiental: temas de economia, política e gestão do meio ambiente. Santa Cruz do Sul: Edunisc.

Tachizawa, T. (2002). Gestão Ambiental e Responsabilidade Social Corporativa: estratégias de negócios focadas na realidade brasileira. São Paulo: Atlas.

UNIDO. (2001).Clenaer production toolkit. Introduction into cleaner production. Volume $1 .$.

Valle, C. E. (2006). Qualidade Ambiental: ISO 14000.( 6. ${ }^{\text {a }}$ Ed.). São Paulo, Editora SENAC. 